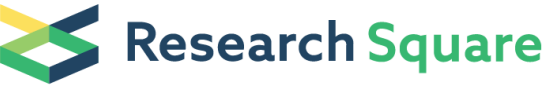 \\ Preprints are preliminary reports that have not undergone peer review. \\ They should not be considered conclusive, used to inform clinical practice, or referenced by the media as validated information.
}

\section{A land-neutral expansion of Brazilian renewable fuel production}

Luis Ramirez Camargo ( $\sim$ luis.ramirez-camargo@boku.ac.at )

University of Natural Resources and Life Science, Vienna https://orcid.org/0000-0002-1554-206X

Gabriel Castro

University of Natural Resources and Life Science, Vienna

Katharina Gruber

University of Natural Resources and Life Sciences, Vienna

Jessica Jewell

Chalmers University of Technology https://orcid.org/0000-0003-2846-9081

Michael Klingler

Department of Geography, University of Innsbruck

Olga Turkovska

University of Natural Resources and Life Sciences, Vienna

Elisabeth Wetterlund

Luleå University of Technology

Johannes Schmidt

University of Natural Resources and Life Sciences, Vienna https://orcid.org/0000-0003-3533-349X

\section{Article}

Keywords: renewable fuel production, biofuels

Posted Date: February 19th, 2021

DOI: https://doi.org/10.21203/rs.3.rs-257691/v1

License: (c) (1) This work is licensed under a Creative Commons Attribution 4.0 International License.

Read Full License 


\section{A land-neutral expansion of Brazilian renewable fuel pro- duction}

Luis Ramirez Camargo ${ }^{1,2,3, *}$, Gabriel Castro ${ }^{1,4}$, Katharina Gruber ${ }^{1}$, Jessica Jewell ${ }^{5}$, Michael Klingler $^{1,6}$, Olga Turkovska ${ }^{1}$, Elisabeth Wetterlund ${ }^{7,8} \&$ Johannes Schmidt $^{1}$

${ }^{1}$ Institute for Sustainable Economic Development, University of Natural Resources and Life Science, Vienna, Austria

${ }^{2}$ Electric Vehicle and Energy Research Group (EVERGI), Mobility, Logistics and Automotive Technology Research

Centre (MOBI), Department of Electrical Engineering and Energy Technology, Vrije Universiteit Brussel, Brussels, Belgium

${ }^{3}$ Flanders Make, 3001 Heverlee, Belgium

${ }^{4}$ Energy Planning Program, Graduate School of Engineering, Federal University of Rio de Janeiro, Rio de Janeiro, Brazil.

${ }^{5}$ Department of Space, Earth and Environment, Chalmers University of Technology

${ }^{6}$ Department of Geography, University of Innsbruck, Innsbruck, Austria

${ }^{7}$ Energy Engineering, Division of Energy Science, Luleå University of Technology, 97187 Luleå, Sweden

${ }^{8}$ International Institute for Applied Systems Analysis (IIASA), A-2361 Laxenburg, Austria

Biofuels are currently the only available bulk renewable fuel. They have, however, limited expansion potential due to high land requirements and associated risks for biodiversity, food security, and land conflicts. We therefore propose to increase output from ethanol refineries in a land-neutral methanol pathway: surplus $\mathrm{CO}_{2}$-streams from fermentation are combined with hydrogen from renewably powered electrolysis to synthesize methanol. We illustrate this pathway with the Brazilian sugarcane ethanol industry using a spatio-temporal model. The fuel output of existing ethanol generation facilities can be increased by $42 \%-49 \%$ or $\sim 100 \mathrm{TWh}$ without using additional land. This amount is sufficient to cover projected growth in Brazilian biofuel demand in 2030 . We identify a trade-off between renewable energy generation technologies: wind power requires the least amount of land whereas a mix of wind and solar costs the least. In the cheapest scenario, green methanol is competitive to fossil methanol at a carbon price of $80 € / \mathrm{tCO}_{2}$.

Biofuels occupy an integral role in netzero emission scenarios ${ }^{1}$, as they are the only bulk re- 
newable alternative to liquid fossil fuels currently available ${ }^{2,3}$. In particular bioethanol production from sugarcane (Saccharum spp.) shows high potential for land-based carbon mitigation ${ }^{4,5}$. Brazil, the largest ethanol producer from sugarcane globally, has put in place a series of policies, such as the National Biofuels Policy (RenovaBio) or the current proposal for a credit subsidized COVID19 Emergency Program to Support the Brazilian Sugar-Energy Sector (Peasse). These policies aim to safeguard the contribution of sugarcane ethanol toward the renewable energy targets of Nationally Determined Contributions (NDCs) and generate new incentives for biofuel production and technological innovation ${ }^{2,6}$.

However, the benefit of such a pathway is controversial due to a number of concerns specific to sugarcane expansion: (1) the land-use intensity of sugarcane causes significant environmental impacts including biodiversity loss, soil degradation, pollution and depletion of water resources ${ }^{7-9}$; (2) the competition for other land uses affects small-scale family agriculture and food security ${ }^{10-12}$, and (3) the high land-use intensity of biofuels has caused fundamental criticism regarding their $\mathrm{CO}_{2}$-savings potential ${ }^{13}$, in particular when taking into account emissions from indirect land-use change ${ }^{9}$.

To tackle these negative impacts of sugarcane ethanol production, several land-efficient production pathways have been proposed. Such pathways increase output by intensifying existing production instead of expanding sugarcane plantations ${ }^{14,15}$ either through converting degraded pastures with agricultural potential into cropland with a concurrent intensification of active pastures ${ }^{16}$ or through second-generation $(2 \mathrm{G})$ ethanol production technology ${ }^{17,18}$. Under $2 \mathrm{G}$ ethanol production, the ligno-cellulosic part of the sugarcane, i.e. the bagasse, is used for ethanol production in addition to the sucrose. When combined with alternative hybrid sugarcane crops which increase the amount of the fibre at the cost of the sucrose content ${ }^{2}$, the increase in land efficiency can reach more than $50 \%^{19} .2 \mathrm{G}$ ethanol, however, comes with the down-side of less surplus electricity production as sugarcane bagasse not used as $2 \mathrm{G}$ feedstock is typically combusted for electricity generation ${ }^{18}$.

Here, we present a new land-neutral methanol pathway and assess by how much the fuel 
output can be increased if the total plantation area is fixed at current levels of ethanol production. This way, the associated negative impacts of sugarcane ethanol expansion are avoided. We propose to synthesize methanol using $\mathrm{CO}_{2}$ from the fermentation process in ethanol plants and $\mathrm{H}_{2}$ produced from electrolysis powered entirely by on-site variable renewable energy sources (VRES). The higher land efficiency of VRES in comparison to biomass increases the land efficiency of combined ethanol and methanol output significantly, while the almost clean $\mathrm{CO}_{2}$-streams from ethanol fermentation allow to produce methanol from $\mathrm{H}_{2}$ and $\mathrm{CO}_{2}$. This is beneficial, as methanol is much easier to handle and transport than pure $\mathrm{H}_{2}{ }^{20}$. We illustrate the land-neutral methanol pathway for the case of the sugarcane ethanol frontrunner Brazil, which has experienced rising expansion of sugarcane plantations into biodiversity hotspots of Amazon, Pantanal and Cerrado biomes during the last decade ${ }^{21,22}$.

Understanding costs and magnitudes of the required infrastructure is a key element for the implementation of the land-neutral methanol pathway. Recent estimates of power-to-methanol processes show that costs are more than double compared to their fossil counterparts ${ }^{23,24}$. However, our proposed pathway includes important elements that can make green methanol more competitive: the size of $\mathrm{H}_{2}$ and $\mathrm{CO}_{2}$ storage is optimized to maximize capital utilization ${ }^{25}$, while the almost pure and low-cost $\mathrm{CO}_{2}$-stream from the ethanol production process can further lower the costs. Consequently, we are able to show that under certain plausible techno-economic assumptions, the $\mathrm{CO}_{2}$ abatement cost from the land-neutral methanol pathway is competitive to other mitigation technologies.

\section{Illustrating the land-neutral methanol pathway}

We optimize power-to-methanol processes at all Brazilian sugarcane plants in a spatially and temporally explicit way that accounts for the seasonality of sugarcane production, and the variability of $\mathrm{PV}$ and wind power at all plant sites (Fig. 1). $\mathrm{CO}_{2}, \mathrm{H}_{2}$, and electricity storage options are incorporated to handle the temporal asynchrony of the electricity and gas streams. The entire process is studied under a variety of technological assumptions in two scenarios. First, we differentiate 
between a scenario with mixed PV and wind power generation (solar-wind scenario), and a scenario with wind power generation only (wind scenario). We do not assess a PV only scenario, as it would not improve on costs or land-use efficiency over the solar-wind scenario. In contrast, the wind scenario can improve on land-use efficiency - at a higher cost - due to the lower land footprint of wind power. Second, we assess how varying techno-economic assumptions regarding annualized electrolyzer costs, efficiency of the electrolysis, and annualized costs of PV generation affect land-use, methanol cost, and system configurations (see methods and supplementary Table 1 for details). The production of green methanol can be easily combined with other land-efficient technologies in ethanol production, as the $\mathrm{CO}_{2}$-streams from fermentation increase proportionally to the amount of ethanol produced. We therefore also explore the implications for the feasibility of the proposed pathway of ethanol production at higher land-use efficiencies.

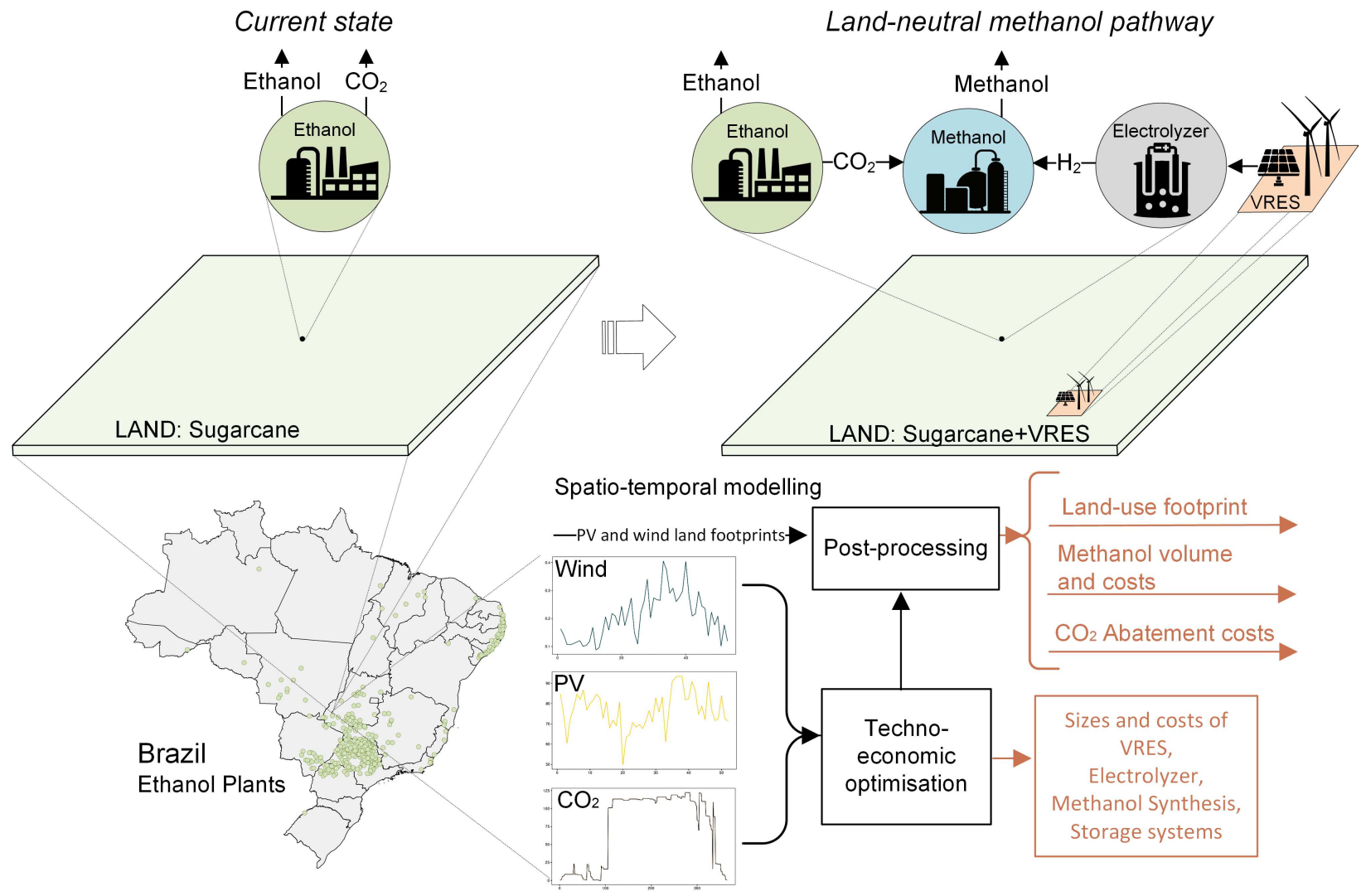

Fig. 1. The proposed land-neutral methanol pathway.

We choose methanol as the final product, as i) the process to derive it from $\mathrm{H}_{2}$ and $\mathrm{CO}_{2}$ is 
comparatively simple, ii) it is a liquid fuel, easy to transport without additional infrastructure, and iii) it has a variety of applications as feedstock for the chemical industry and transportation fuel. In particular, it can complement ethanol in blends of methanol, ethanol, and gasoline ${ }^{26}$. Therefore, it can be used in flex-fuel engines optimised for ethanol-gasoline blends without requiring modifications to the engine or vehicle, as well as in heavy-duty long-distance road and maritime transport ${ }^{27}$.

\section{Combining methanol with ethanol production significantly improves land-use efficiency}

The additional output in energetic terms increases by $43 \%-49 \%$ when implementing the landneutral methanol pathway. The lower value results from the solar-wind scenario, where a significant amount of PV generation capacity is installed. The higher value for the wind scenario is a result of the much smaller direct footprint of wind turbines, as spacing areas between turbines can be used for sugarcane production (Methods). If the same volume of sugarcane ethanol would be produced at the average Brazilian land-use efficiency, between $23,000 \mathrm{~km}^{2}$ to $27,000 \mathrm{~km}^{2}$ of additional land would instead be required ${ }^{28}$.

The available amount of methanol, i.e. about $100 \mathrm{TWh}$, could cover several times the domestic fuel demand for shipping ${ }^{29}$ or $28 \%$ of freight transport in the country ${ }^{30}$. The average land-use efficiency of today's Brazilian ethanol production is $3.7 \mathrm{GWh} / \mathrm{km}^{2}$. The combined land-use efficiency of methanol and ethanol production for the wind scenario is $5.5 \mathrm{GWh} / \mathrm{km}^{2}$, and for the solar-wind scenario is $5.2 \mathrm{GWh} / \mathrm{km}^{2}$. While the wind scenario outperforms the solar-wind scenario in land-use efficiency, it is more expensive under all techno-economic assumptions.

The high land-use efficiency of the land-neutral methanol pathway is highlighted for all installations and the two scenarios in Fig.2. The figure also illustrates that variability within the scenarios is very high for the wind scenario and very low for the solar-wind scenario. This is a consequence of highly variable wind conditions and comparably low heterogeneity in solar radiation between locations. There are some outliers in terms of land-use efficiency for some facilities in the solar-wind scenario in the North-East and the South-East. These facilities are located close 


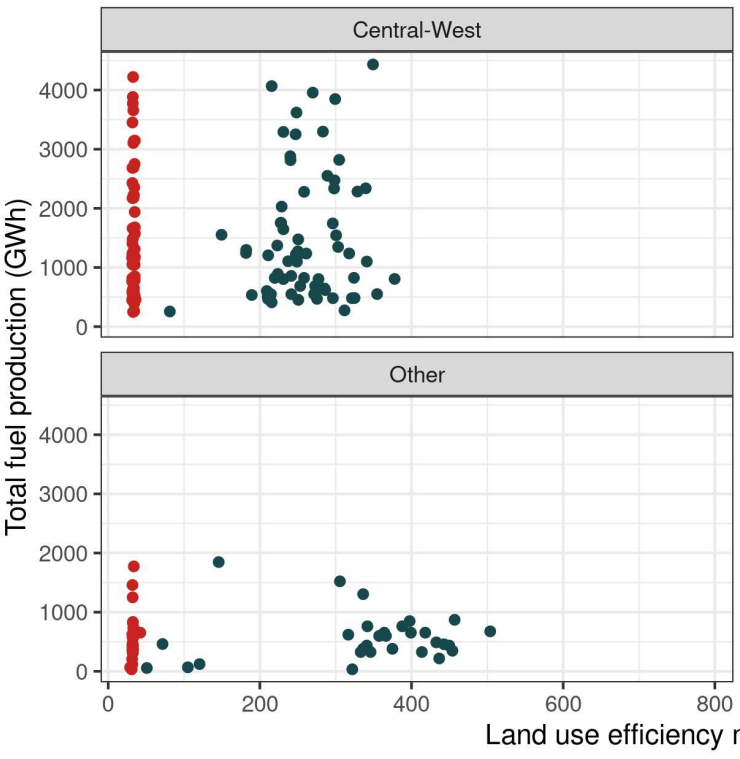

Fig. 2. Land-use efficiency of methanol production vs. total fuel production for all Brazilian facilities.

to the coast where wind resources are much higher than inland, allowing for a mix of wind and PV. At all other locations, the wind share is very low or even 0 , highlighting the low wind resources at most sugarcane production sites. Facilities that have higher land-use efficiency in the solar-wind scenario, however, also have low total fuel production potentials due to currently low amounts of ethanol production at those sites. Lowering land-use and costs by incorporating sites with excellent wind conditions is therefore possible only for a small share of overall production, i.e. $1.5 \%$ of total methanol production at 14 locations. Ethanol plants, and therefore the potential for combined ethanol \& methanol production, are highly concentrated in two regions; the Central-West, and the South-West, both states with low wind resources. In this area, the state of São Paulo is the most important one, producing $45 \%$ of total Brazilian sugarcane ethanol volume (Supplementary Fig. $1)$.

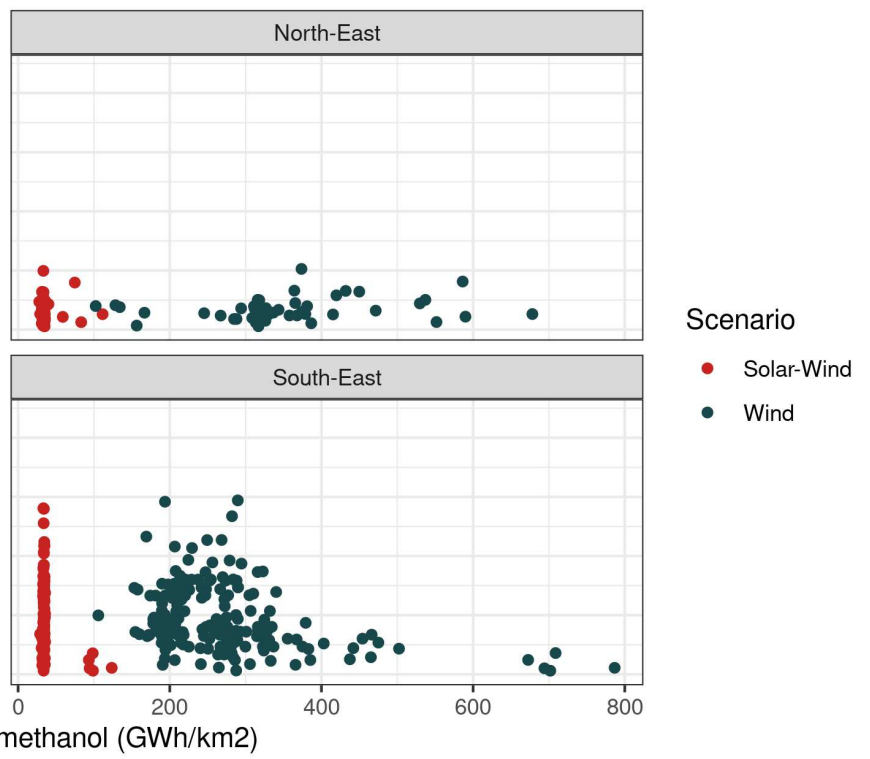

The relative increase in land-use efficiency - made possible by the land-neutral methanol pathway - decreases if the sugarcane-to-ethanol land-use efficiency increases (Supplementary Fig. 2) for a simple reason: at high sugarcane-to-ethanol efficiency increases, substituting sugarcane by VRES will not save as much land as at a lower efficiency. The sugarcane-to-ethanol efficiency has increased by around $1 \%$ every 3 years in the period $2005-2020^{31}$. If efficiency gains remain 
at this order of magnitude, impacts on the overall efficiency of the land-neutral methanol pathway are very low. However, a technological leap such as an upgraded conversion technology (i.e., 2G ethanol), potentially combined with sugarcane breeds of higher yield ${ }^{2}$, could allow for a one-off increase in ethanol output by 50\%. At this value, the land-use efficiency gain implied by the landneutral methanol pathway drops by $3 \%$ in the solar-wind scenario (from $43 \%$ to $40 \%$ ), and by $0.6 \%$ in the wind scenario (from $48.9 \%$ to $48.3 \%$ ). We also assess how much sugarcane-to-ethanol efficiency would need to increase to make adding methanol from renewable power inefficient in terms of land-use: an increase of ethanol land-use efficiency by 10 times in the solar-wind scenario, and by 70 times in the wind scenario would decrease total output if substituting sugarcane for VRES. This magnitude clearly illustrates that the land-neutral methanol pathway can provide landuse efficiency improvements under any realistic future increase in sugarcane-to-ethanol land-use efficiency.

\section{Cost of methanol determined by electrolysis and solar PV}

The methanol cost of the land-neutral methanol pathway strongly depends on uncertain costs of the technological components. We test a range of plausible cost estimates from the highest where costs stay at today's level - to the lowest - where costs fall to around two thirds (PV) and one third (electrolyzers) of what they are today (Methods, Supplementary Table 1). We find that the cost of methanol in the proposed pathway is most significantly impacted by the costs and efficiency of the electrolyzer, and the cost of solar PV, whereas assumptions on the costs of storage technologies and wind power and the selected weather year have comparably minor impact on our results (Supplementary Note 1). The spread in methanol costs across the sets of assumptions is significant but is consistently lower under the solar-wind scenarios than the wind scenarios by about 1.5 to 2.5 times under similar techno-economic assumptions (Figure 3). This implies that the wind scenario is by far not cost competitive and we therefore do not discuss it in the following. We emphasize here that these particular results are not generalizable but are specific to the wind resources at most sugarcane plants: at some limited locations where wind speeds are higher, wind power is added to the cost-optimal mix. 
In the solar-wind scenario, average production costs of methanol vary due to different technoeconomic assumptions between about $0.07 € / \mathrm{kWh}$ and about $0.14 € / \mathrm{kWh}$, i.e., the costs double between sets of assumptions. Compared to fossil methanol $(0.04 € / \mathrm{kWh})$, this is an increase in production costs between $67 \%$ and $240 \%$. The higher end of our cost estimates matches recently modeled costs of producing methanol in 2030 with alkaline electrolyzers, $\mathrm{CO}_{2}$ from direct air capture and electricity from PV power ${ }^{32}$. Our carbon abatement costs are between $80 € / \mathrm{tCO}_{2}$ and $320 € / \mathrm{tCO}_{2}$, when compared to fossil production of methanol from steam reforming and synthesis gas conversion of natural gas (See Supplementary Note 2).

The supply curves show that differences in the climate conditions for VRES generation and the load profiles of $\mathrm{CO}_{2}$ have an impact on methanol costs. I.e., when assessing variation in methanol cost within one set of techno-economic assumptions, the methanol cost of the most expensive location is by 20\%-57\% higher than that of the cheapest one, depending on which underlying techno-economic assumptions are chosen. To assess in detail the impact of climate conditions and $\mathrm{CO}_{2}$-profile on methanol cost, we ran a regression model for the solar-wind scenario. We select one set of techno-economic assumptions (see Supplementary Note 3 for details) and regress average capacity factors of PV, a dummy variable which indicates if the wind power capacity factor is higher than 0.3 , and the length of the $\mathrm{CO}_{2}$-supply season on methanol costs. Our regression explains $64 \%$ of variation in the data. Average PV capacity factors are strongly significant and inversely related to cost: an increase in the capacity factor of 0.01 would decrease cost by 0.2 $€ C e n t / k W h$ on average. Capacity factors vary by at most 0.04 between locations, thus solar radiation can explain up to $0.8 € C$ ent $/ \mathrm{kWh}$ or $8 \%$ of variation in costs between locations with lowest and highest possible solar radiation. This is caused by lower investment requirements into PV and electrolyzers at those locations. The differences between locations with wind power capacity factors below or above 0.3 , respectively, is on average $0.5 €$ Cent or $5 \%$. Single locations with exceptionally good wind conditions, however, show substantially lower methanol cost. Counter-intuitively, the longer the $\mathrm{CO}_{2}$-supply period, the higher the final methanol cost. This is a consequence of very low $\mathrm{CO}_{2}$-storage costs: if the $\mathrm{CO}_{2}$-supply is concentrated in a short period of time, the $\mathrm{CO}_{2}$ storage can be filled up quickly and the variation in renewable power supply can be balanced by the $\mathrm{CO}_{2}$ 
storage at most times. However, if the $\mathrm{CO}_{2}$ supply is stretched over a long period, the $\mathrm{CO}_{2}$ storage needs time to fill up and, in some circumstances, renewable power supply will be higher than the currently stored $\mathrm{CO}_{2}$. As storing electricity or $\mathrm{H}_{2}$ is much more expensive than storing $\mathrm{CO}_{2}$, instead higher renewable electricity generation facilities and higher methanol synthesis capacities are installed at those locations to compensate for curtailed power and methanol production at the start of the season. The effect can become relatively large for extreme cases: $\mathrm{a} \mathrm{CO}_{2}$ supply season which is 100 days shorter will decrease the methanol costs by $0.4 € C e n t$. The difference between the shortest and the longest period is 270 days, so in total, ceteris paribus, the factor could explain about $1.1 € C e n t$ or $12 \%$ of differences in costs. Multi-annual $\mathrm{CO}_{2}$ storage is one way of addressing this challenge, but was not assessed by us.
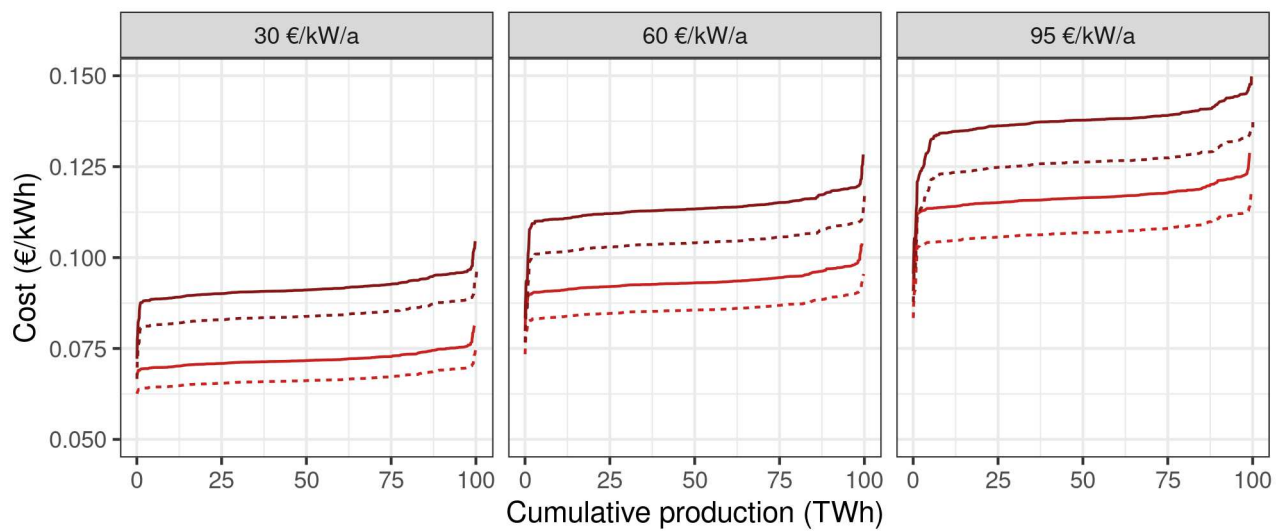

$$
\begin{aligned}
& \text { PV costs } \\
& -35 € / \mathrm{kW} / \mathrm{a} \\
& -53 € / \mathrm{kW} / \mathrm{a}
\end{aligned}
$$

Efficiency electrolyzer

$-0.63$

$\cdots \cdot 0.69$
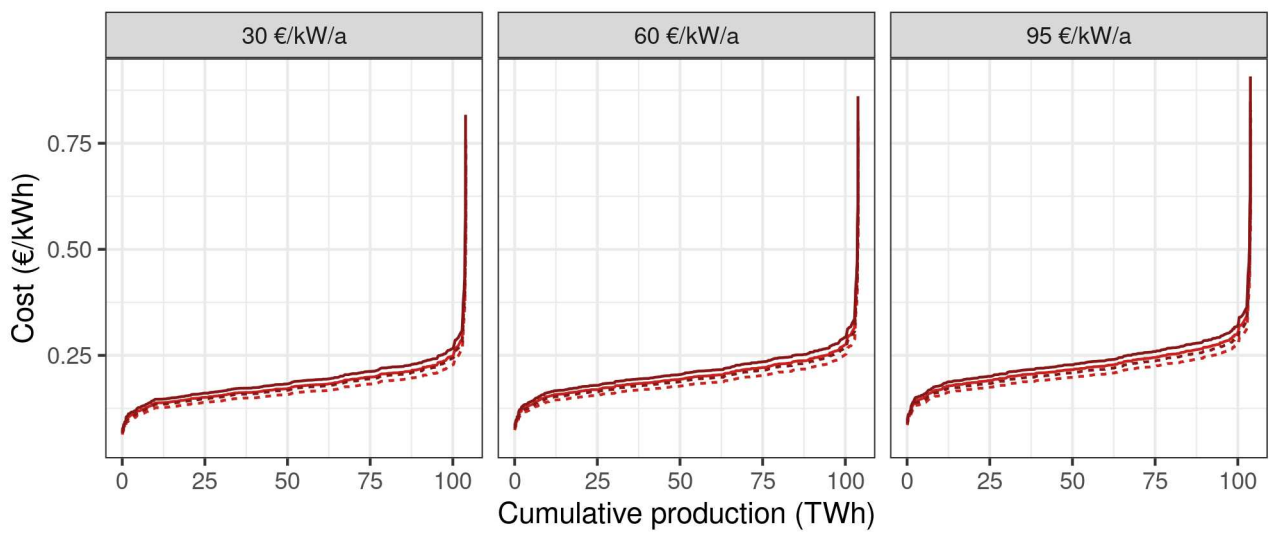

Wind costs

$-118 € / \mathrm{kW} / \mathrm{a}$

$-128 € / \mathrm{kW} / \mathrm{a}$

Efficiency electrolyzer

$-0.63$

$\cdots 0.69$

Fig. 3. Cost-supply curves for all scenarios and costs assumptions. Upper: solar-wind scenario. Lower: wind scenario. From left to right: annualized electrolyzer cost assumptions. 


\section{Methanol plants components sizing}

Here, we show the size of the different technical components in GW, GWh or Kt used in the landneutral methanol pathway under different techno-economic assumptions (Fig. 4). In general there is at least one order of magnitude more PV capacity than wind power capacity in the solar-wind scenarios due to low wind resources available at sugarcane plantation sites. In terms of storage, there is about three orders of magnitude more $\mathrm{CO}_{2}$ storage than $\mathrm{H}_{2}$ storage - and battery storage is not installed under any of the techno-economic assumptions. This can be explained by the fact that $\mathrm{CO}_{2}$ storage is the least costly form of storage and therefore balances the system seasonally and hourly. If the process is installed at all locations in Brazil, the required capacities of the components are large: PV capacities of over $100 \mathrm{GW}$ and electrolyzer capacities of between 60 and $80 \mathrm{GW}$ would have to be installed, depending on the scenario. In total, $\mathrm{CO}_{2}$-storage capacities of up to 10 $\mathrm{MtCO}_{2}$ are necessary, as a constant $\mathrm{CO}_{2}$ stream has to be guaranteed throughout the year, while the fermentation process runs only seasonally. The scale of these installations is huge, e.g. for PV it is one order of magnitude higher than currently installed PV generation capacity in the Brazilian electric system ${ }^{29}$. Both $\mathrm{CO}_{2}$-storage as well as electrolyzer capacities are not deployed at scale in Brazil, and corresponding deployment challenges will emerge.

The mean size of PV installations at plants is around $300 \mathrm{MW}$. While this is less than half the size of the currently largest PV installation in Brazil (São Gonçalo) ${ }^{33}$, the largest installation would be over $1.5 \mathrm{GW}$, which is about the scale of the largest installations globally ${ }^{34}$. The largest ethanol plants require storage sizes of almost $190 \mathrm{KtCO}_{2}$, while the mean size is at $30 \mathrm{KtCO}_{2}$.

The pattern of component sizing is robust to changing the underlying techno-economic assumptions: a decrease in electrolysis efficiency increases the size of electricity generation and electrolyzer components due to higher losses in the production of hydrogen, but the methanol synthesis size and the size of $\mathrm{CO}_{2}$ and $\mathrm{H}_{2}$ and storages remain almost unaffected. Higher PV costs shift generation slightly to wind power, but the effect is minor, illustrating that PV outperforms wind power by far at the given locations in terms of cost-efficiency. A change in electrolyzer cost drives changes in electrolyzer size, but the effect is relatively small, given that a three times higher 


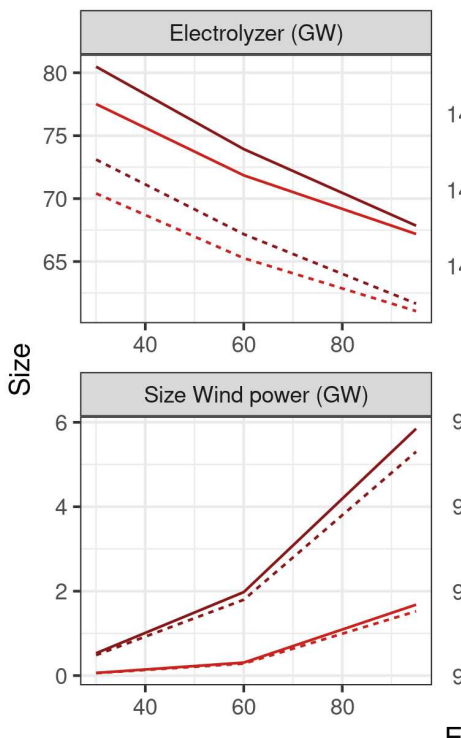

electrolyzer cost reduces the size by only about $15 \%$. While methanol costs are therefore uncertain, the sizing of components is robust to strong parameter variations.
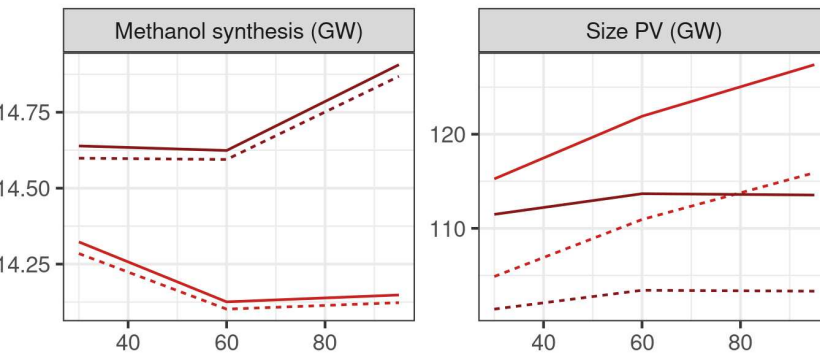

Efficiency electrolyzer

$-0.63$

$\cdots 0.69$
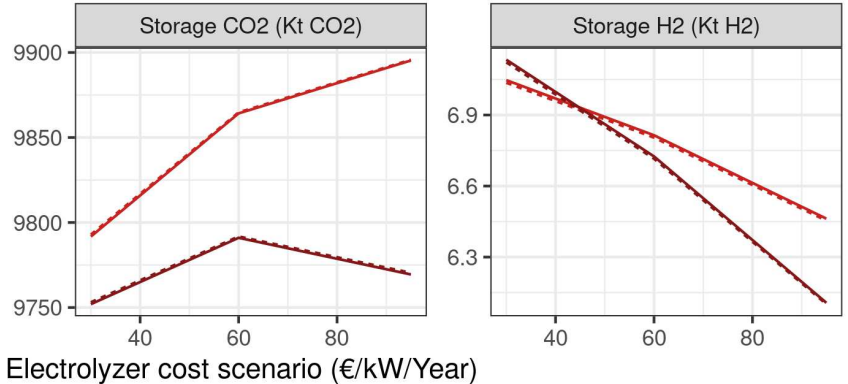

PV Cost scenario

- $35 € / \mathrm{kW} / \mathrm{a}$

- $53 € / \mathrm{kW} / \mathrm{a}$

Fig. 4. Sizes of generation, conversion and storage components (sum of all locations) in the solar-wind scenario.

\section{Discussion}

The implementation of the land-neutral methanol pathway would substantially decrease Brazilian $\mathrm{CO}_{2}$ emissions by about $27 \mathrm{MtCO}_{2}$ annually, which amounts to $7 \%$ and $3 \%$ of total Brazilian $\mathrm{CO}_{2}$ emissions related to energy generation and land-use change, respectively ${ }^{35}$. Similar to biofuel production, Brazil could become a forerunner in synthetic fuel production. This could in the longterm pave the way to future fully synthetic fuel production using direct air carbon capture instead of carbon captured by biomass, thus increasing output on the same land by at least a factor of 10 compared to today's ethanol pathway ${ }^{19}$.

To achieve the full potential of social, environmental and industrial co-benefits of the landneutral methanol pathway and to make it economically competitive, a supportive land-use policy, which enforces land-neutrality of Brazilian biofuel production, would have to be implemented. Only under such a policy could potential rebound effects from increased demand ${ }^{36}$ be prevented. At the same moment, such a land-neutral policy would increase biofuel prices, making our pro- 
posed land-neutral methanol pathway more competitive. In contrast, current political practice is weakening Brazilian land conservation policies by lifting a ban on sugarcane expansion in the Amazon and the Pantanal ${ }^{21}$ : under such conditions and without additional carbon pricing, the new technologies are not competitive, even under optimistic assumptions on technology cost. Policy makers also have to consider that the highly capital and land intensive pathway may lead to increasing the profit share of capital and land owners at the cost of the labour share, compared to ethanol production only.

There are also uncertainties for the land-neutral methanol pathway, which can only partly be addressed by today's policy and decision makers: short-term demand reductions for fuels due to the COVID-19 crisis and long-term demand reductions due to electrification of transport will have a negative impact on the demand for liquid, fossil fuels. At the same time, under strict climate change mitigation scenarios, demand for renewable fuels will increase as they are fundamental to fully decarbonize industry, heavy-duty transportation and electricity systems. The short and medium-term development of the Brazilian industry is therefore controversially discussed and a future decrease of production cannot be ruled out ${ }^{37}$. There is also uncertainty about the costs of future PV generation and, to an even greater extent, of electrolyzers, which strongly affect the cost-competitiveness of the land-neutral methanol pathway. The development of technological cost will partly depend on global investments into research and development and deployment of these technologies. Still, the land-neutral methanol pathway alone would increase demand for these technologies to a scale that would allow building up a national industry in the synthetic fuel sector, thus substantially lowering cost. Finally, little is known about the environmental impacts of substituting sugarcane plantations by PV and wind turbines. Presumably, most environmental impacts will decrease ${ }^{38}$. However, life cycle analysis shows that in some cases, the negative impacts of solar PV on water ecotoxicity exceed those of biomass-based energy ${ }^{38}$. Also, volant wildlife species are at risk from wind turbines ${ }^{39,40}$, as are environmentally vulnerable areas ${ }^{41}$. The analysis of these uncertainties is crucial for e.g. biodiversity conservation and can best be tackled by future research. 


\section{Methods}

Producing methanol from surplus $\mathrm{CO}_{2}$ and renewable hydrogen. Sugarcane to ethanol plants in Brazil use mostly first-generation conversion technology which produces ethanol by distillation of sugarcane juice. Ethanol plants are energy self-sufficient thanks to Combined Heat and Power (CHP) plants, where bagasse is burnt to produce electricity and process heat ${ }^{28,42}$. Surplus electricity is exported to the electric grid. Bagasse can alternatively be used as feedstock for $2 \mathrm{G}$ biofuel production, thus increasing the fuel output, while decreasing the electricity output of the plant. We propose to upgrade existing sugarcane plants by adding a water electrolyzer, driven by VRES generation, and a methanol synthesis unit which combines $\mathrm{H}_{2}$ from the electrolyzer with $\mathrm{CO}_{2}$ separated from the ethanol fermentation process. We assume that the electrolyzer is not connected to the electricity grid, but that it relies on electricity generated by VRES locally. This assumption is justified as electricity demand for electrolysis would be substantial at large ethanol facilities. The required transmission infrastructure is not available currently and building it would be very costly. More importantly, the generation of electricity on-site is less costly than paying wholesale market prices plus grid fees.

We developed a linear optimization model (LP) to minimize the costs of VRES-based synthetic methanol production (See supplementary Note 4). The methanol production process is an adaptation of the electrochemical methanol process model proposed by Hannula ${ }^{43}$, and the sugar cane ethanol refinery model proposed by Gnansounou et al. ${ }^{44}$. The detailed model with streams of sugarcane, electricity, heat, $\mathrm{CO}_{2}$, ethanol, and methanol in the facility derived from these two sources was simplified to streams of electricity, $\mathrm{H}_{2}$ and $\mathrm{CO}_{2}$ as functions of the amount of produced ethanol (see Supplementary Fig. 7).

Based on the premise of energy self-sufficiency of the installation, we assumed that the CHP runs always when heat is required for the ethanol production process, but that surplus electricity is not used in the electrolyzers. Currently, surplus electricity from the CHP is exported to the grid. Assuming internal use would likely indirectly affect $\mathrm{CO}_{2}$ emissions in the Brazilian electricity system. To make our assessments of carbon abatements independent of those indirect impacts, we do 
not take changes in electricity exports from the CHP or VRES into account. The model was solved over one year of operation for each installation individually, as there are no interactions between facilities. We assumed that the sizing of components at the existing sugarcane refinery remains fixed, while we optimized the size of PV and wind power generation facilities, electrolyzers, and methanol synthesis reactors, as well as electricity, $\mathrm{H}_{2}$ and $\mathrm{CO}_{2}$ storage sizes. All processes were simulated on an hourly basis. The simulation year does not start on the 1st of January, but at the moment when the cumulative sum of $\left(\mathrm{CO}_{2}\right.$-stream - mean $\left(\mathrm{CO}_{2}\right.$-stream $\left.)\right)$ is minimal: this coincides with the moment in the year when, optimally, the $\mathrm{CO}_{2}$ storage is completely emptied and starts to be filled again. As production profiles for the installations are homogenous for all installations within one state, within each state the simulation year starts at the same point in time.

A synthetic data set of the Brazilian ethanol industry. At the moment, there is no single or consolidated source of data on ethanol generation plants in Brazil. In contrast to previous studies, we therefore have developed our own consolidated database. This includes data from three official sources, i.e. the Energy research company (EPE-Empresa de Pesquisa Energética), the National Agency of Oil, Natural Gas and Biofuels (ANP-Agência Nacional do Petróleo, Gás Natural e Biocombustíveis), and the Ministry of Agriculture (MAPA-Ministério da Agricultura, Pecuária e Abastecimento). Details can be found in Supplementary Note 5.

Little is known about the temporal production profiles in ethanol plants. In all related modeling approaches (e.g. ${ }^{17,28}$ ), a certain number of hours of continuous generation is assumed, as the daily or hourly operation profile of the plants is irrelevant in these studies. The seasonality of ethanol production, as well as intra-day operation variability, is however crucial to our approach. We therefore approximated the time profile of ethanol production using the CONAB statistics for sugar cane grinding on a state basis ${ }^{45}$. This source included data on the number of operation months, running days, and hours of operation per day, as well as processing volume shares by month and state. We used the volume shares to define in which months plants are operating, the total number of running days to restrict the length of the season, and accommodated the operation hours in the middle of each operating day to determine the hours of operation (e.g., a plant with 
20 hours of operation runs between 02:00 and 22:00). The volume of ethanol generation per hour is equal to the total annual ethanol production divided by the number of operation days per year and the number of operating hours per day. Due to limited data availability, temporal profiles of sugarcane production therefore only differ between states. However, we scaled the level of production to the sizes of the individual plants. Assuming that sugar cane fermentation and therefore $\mathrm{CO}_{2}$ formation occurs at the same pace as ethanol production, the $\mathrm{CO}_{2}$ emission time series were calculated for each installation using the hourly ethanol generation profiles (see Supplementary Fig. 8).

Photovoltaic energy generation potential and footprint. Hourly electricity generation of PV installations was calculated for the location of each ethanol plant using PV LIB ${ }^{46}$ and ERA5$\operatorname{land}^{47}$ data. Time series were generated assuming the use of monocrystalline panels with a fixedtilt orientation towards north and inclination equal to the latitude. This configuration is a common approximation for installations to maximize the output of electricity per year. The approach has been validated against hourly electricity generation data of PV installations in Chile ${ }^{48}$. Since there are no PV installations close to ethanol plants which are available for validation, we compared the average yearly and monthly generation totals of PV electricity output calculated with our approach to solargis data ${ }^{49}$ for each location. The correlation, relative mean bias error and relative root mean squared error are on average $0.99,0.08$ and 0.09 respectively (For details see the repository). This implies a slight overestimation of the PV production compared to solargis. The average capacity factors of solar PV installations at all ethanol plants locations are presented in Supplementary Fig. 9.

The land footprint of PV was estimated for eight large PV plants in Brazil, the locations of which were derived from a dataset provided by ANEEL ${ }^{33}$. Using the measuring tool in Google Earth, the extension of these plants was measured in two different ways. In a first step, the area covered by panels was measured. In a second step, the panels and the surroundings used for roads, in-between panel space, and electrical infrastructure were also determined (detailed results are provided in supplementary tables 8 and 9). The number relevant for our model is the total land 
requirement including spacing and infrastructure. As an approximation, $10 \mathrm{~m}^{2} / \mathrm{kWp}$ was assumed for the panel area, with $25-30 \mathrm{~m}^{2} / \mathrm{kWp}$ needed for the PV plant including infrastructure. These results are comparable to values in the literature. Detailed results are provided in supplementary table 10.

Wind energy generation potential and footprint. Potential wind power generation at the location with the highest wind speed in a perimeter of $40 \mathrm{~km}$ around each ethanol plant location was simulated using a power curve based model. As a climate data source, we used hourly ERA5 reanalysis wind speed data with a spatial resolution of $30 \mathrm{~km}$ and the Global Wind Atlas Version 2 with a spatial resolution of $250 \mathrm{~m}$ for mean bias correction at a higher spatial resolution. The model has been validated against generation data in Brazil, the United States, South Africa and New Zealand and shows satisfactory simulation quality, i.e. the RMSE is below 0.4 for most locations $(0.16 \text { on average })^{50}$. On average, the modelled wind power generation underestimates observed generation by around $4 \%$ of the capacity factor in Brazil. Two turbine types in different IEC wind classes were simulated: Nordex N100 3.3 MW (IEC class I) and Vestas V90 2.0 MW (IEC class II) ${ }^{51}$. Losses due to wake were not considered, assuming that the spacing between turbines is sufficiently large. Time series of average weekly capacity factors at all locations for the two turbine types are presented in Supplementary Fig. 10. We estimated land requirements for wind turbines by measuring the area of the existing turbine pads and roads that connect them via Google Earth. Rio Grande do Norte was used as a benchmark for estimating land requirements as it has the largest number of installed wind parks among all federal states in Brazil ${ }^{52}$. We measured four wind parks i.e., two wind parks with a turbine capacity of $2 \mathrm{MW}$ and two parks with a turbine capacity of $3 \mathrm{MW}$. Based on these parks, we estimated the average turbine pad area per MW with and without a road for the different turbine capacities. Hence, the area of sugarcane plantations that needs to be replaced by wind turbines was estimated using the respective pad and road requirements per MW. Our estimates for $2 \mathrm{MW}$ and $3 \mathrm{MW}$ turbine capacity, 0.33 and $0.48 \mathrm{ha} / \mathrm{MW}$ respectively, are in-line with values reported by Denholm et al. ${ }^{53}$ i.e., an average of 0.3 ha/MW with a standard deviation of $0.3 \mathrm{ha} / \mathrm{MW}$ for US wind parks. 
Cost assumptions and scenarios. The annualized costs of the individual systems were calculated assuming an interest rate of 8\%, as well as lifetime, CAPEX and OPEX, which vary depending on the technology. The PV and wind power installation lifetime was set to 20 years. PV investment costs in the low cost scenario were derived from Vartiainen et al. ${ }^{54}$ and the Danish Energy Agency ${ }^{55}$ at around $290 € / \mathrm{kW}$ for 2030 . The high costs represent investment costs in 2020 . For wind power, a similar approach was taken. Battery lifetime was set to 15 years, and CAPEX and OPEX were taken from the 2020 and 2030 scenario in Vartiainen et al. ${ }^{54}$. Other technological assumptions were collected from a thorough literature review. $\mathrm{H}_{2}$ storage costs were assumed based on the numbers in Kruck et al. ${ }^{56}$ and counterchecked with other publications, which presented values in a similar range ${ }^{51,57}$. For the estimation of $\mathrm{CO}_{2}$ storage costs, we consulted a range of studies ${ }^{58,59}$. For the widest possible range, the $\mathrm{CO}_{2}$ storage costs of the lowest low-cost scenario and the highest highcost scenario were assumed for the model. The costs of capturing the $\mathrm{CO}_{2}$ from the fermentation process were assumed to be $10 € / \mathrm{tCO}_{2}$ in all scenarios, which is the highest cost reported in our selection of publications (see Supplementary Table 3). We assumed that alkaline electrolyzers are used. These have lower ramping capabilities than polymer electrolyte membranes (PEM). They should, however, be able to fully ramp production in less than one hour, which is compatible with ramps in renewable generation, in particular if small buffering batteries are included in the system. Likewise, limited curtailment can help in stabilizing ramping rates. The costs for electrolyzers are highly variable in literature and we therefore covered a wide range of cost assumptions, as outlined in Supplementary Table 1. We tested the impact of different cost assumptions in 24 different scenarios presented in the main text. Additional variations, i.e. a total of 96 scenarios, are presented in Supplementary Note 1. The 24 main scenarios consist of two different VRES configuration alternatives (only wind and mixed solar and wind), three different assumptions on electrolyzer costs, two different assumptions on electrolyzer efficiency, and two different assumptions on the costs of solar PV installations (see Supplementary Table 1). For storage costs, we assumed the upper bound on the cost range shown in Supplementary Table 1, while for wind turbines we assumed the lower bound. An additional sensitivity analysis in Supplementary Note 1 also varied these cost assumptions in 96 scenarios, but the impacts were minor. Also, we tested the impact of using three 
different weather years on results in 24 scenarios (Supplementary Fig. 3).

Limitations and areas for future research. The proposed spatio-temporal energy model is a perfect foresight model, as annual supply of $\mathrm{CO}_{2}$, and generation of $\mathrm{PV}$ and wind power are assumed to be known in advance. This makes the sizing of components fit the particular parameters perfectly. However, the sensitivity analysis of climate input shows that the differences in necessary VRES and storage capacities between different weather years are below 10\%. We, therefore, are confident that the sizing of components would, in principle, work and that during operation, limited foresight would not affect production costs much. We did not implement site-specific restrictions for storing $\mathrm{CO}_{2}$ or $\mathrm{H}_{2}$, which relies on natural formations such as saline aquifers or depleted oil and gas fields. As quantities are quite significant in particular for $\mathrm{CO}_{2}$, restrictions may arise on feasible storage amounts, although on overall significant $\mathrm{CO}_{2}$ storage is expected to be available in Brazil $^{60}$. Such restrictions should be assessed in future work, with a particular focus on assessing alternatives in underground pipe storage of $\mathrm{CO}_{2}$. At the moment, however, pipe storage seems to be economically infeasible for seasonal $\mathrm{CO}_{2}$ storage purposes, based on assessments of costs of natural gas storage in pipes ${ }^{56}$. The related land-use of $\mathrm{CO}_{2}, \mathrm{H}_{2}$, and electrical storage was also disregarded, as it is expected to be insignificant, in particular for $\mathrm{CO}_{2}$ and $\mathrm{H}_{2}$ underground storage. Furthermore, the model does not allow sugarcane storage which could contribute to balance the strong seasonality of sugarcane availability as an alternative to $\mathrm{CO}_{2}$ storage. However, storage may cause degradation of the stored sugarcane unless energy-intensive cooling is used ${ }^{61}$. We also neglected local water requirements for the electrolyser, as the input was estimated minor ${ }^{62}$, especially compared to water needs of sugarcane plantations. There are also significant uncertainties associated with the approach we used to derive production profiles for ethanol plants. However, these have minor impacts on results, as significant $\mathrm{CO}_{2}$-storage is deployed at all installations anyhow.

\section{References}

1. van Vuuren, D. P. et al. Alternative pathways to the $1.5^{\circ} \mathrm{C}$ target reduce the need for negative emission technologies. Nature Climate Change 8, 391-397 (2018).

2. Grassi, M. C. B. \& Pereira, G. A. G. Energy-cane and renovabio: Brazilian vectors to boost 
the development of biofuels. Industrial Crops and Products 129, 201-205 (2019).

3. Jaiswal, D. et al. Brazilian sugarcane ethanol as an expandable green alternative to crude oil use. Nature Climate Change 7, 788-792 (2017).

4. Field, J. L. et al. Robust paths to net greenhouse gas mitigation and negative emissions via advanced biofuels. Proceedings of the National Academy of Sciences 117, 21968-21977 (2020).

5. Canadell, J. G. \& Schulze, E. D. Global potential of biospheric carbon management for climate mitigation. Nature Communications 5, 5282 (2014).

6. Novato, M. \& Lacerda, M. I. Renovabio-towards a new national biofuel policy and a truly sustainable world. Innovative Energy \& Research 6, 1-2 (2017).

7. Cherubin, M. R. et al. Soil quality indexing strategies for evaluating sugarcane expansion in brazil. PLOS ONE 11, e0150860 (2016).

8. Foley, J. A. Global consequences of land use. Science 309, 570-574 (2005).

9. Lapola, D. M. et al. Indirect land-use changes can overcome carbon savings from biofuels in brazil. Proceedings of the National Academy of Sciences 107, 3388-3393 (2010).

10. Albuquerque Frate, C. \& Brannstrom, C. "will brazil's ethanol ambitions undermine its agrarian reform goals? a study of social perspectives using q-method". Journal of Rural Studies 38, 89-98 (2015).

11. Benites-Lazaro, L. L., Giatti, L. L., Sousa Junior, W. C. \& Giarolla, A. Land-water-food nexus of biofuels: Discourse and policy debates in brazil. Environmental Development 33, 100491 (2020).

12. de Andrade Junior, M. A. U., Valin, H., Soterroni, A. C., Ramos, F. M. \& Halog, A. Exploring future scenarios of ethanol demand in brazil and their land-use implications. Energy Policy 134, 110958 (2019). 
13. Staples, M. D., Malina, R. \& Barrett, S. R. H. The limits of bioenergy for mitigating global life-cycle greenhouse gas emissions from fossil fuels. Nature Energy 2, 16202 (2017).

14. dos Santos, J. S. et al. Characterising the spatial distribution of opportunities and constraints for land sparing in brazil. Scientific Reports 10, 1946 (2020).

15. Phalan, B., Onial, M., Balmford, A. \& Green, R. E. Reconciling food production and biodiversity conservation: Land sharing and land sparing compared. Science 333, 1289-1291 (2011).

16. Alkimim, A., Sparovek, G. \& Clarke, K. C. Converting brazil's pastures to cropland: An alternative way to meet sugarcane demand and to spare forestlands. Applied Geography 62, 75-84 (2015).

17. Khatiwada, D., Leduc, S., Silveira, S. \& McCallum, I. Optimizing ethanol and bioelectricity production in sugarcane biorefineries in brazil. Renewable Energy 85, 371-386 (2016).

18. Dias, M. O. S. et al. Second generation ethanol in brazil: Can it compete with electricity production? Bioresource Technology 102, 8964-8971 (2011).

19. Schmidt, J. et al. A new perspective on global renewable energy systems: why trade in energy carriers matters. Energy \& Environmental Science (2019).

20. Olah, G. A., Mathew, T., Goeppert, A. \& Surya Prakash, G. K. Difference and significance of regenerative versus renewable carbon fuels and products. Topics in Catalysis 61, 522-529 (2018).

21. Lima, M. et al. Sugarcane: Brazilian public policies threaten the amazon and pantanal biomes. Perspectives in Ecology and Conservation 18, 210-212 (2020).

22. Ferrante, L. \& Fearnside, P. M. Amazon sugarcane: A threat to the forest. Science (2018).

23. Bos, M. J., Kersten, S. R. A. \& Brilman, D. W. F. Wind power to methanol: Renewable methanol production using electricity, electrolysis of water and $\mathrm{co}_{2}$ air capture. Applied Energy 264, $114672(2020)$. 
24. Zhang, H. \& Desideri, U. Techno-economic optimization of power-to-methanol with coelectrolysis of $\mathrm{co}_{2}$ and $\mathrm{h}_{2} \mathrm{O}$ in solid-oxide electrolyzers. Energy 199, 117498 (2020).

25. Gorre, J., Ortloff, F. \& van Leeuwen, C. Production costs for synthetic methane in 2030 and 2050 of an optimized power-to-gas plant with intermediate hydrogen storage. Applied Energy 253, 113594 (2019).

26. Turner, J. W. G. et al. Extending the role of alcohols as transport fuels using iso-stoichiometric ternary blends of gasoline, ethanol and methanol. Applied Energy 102, 72-86 (2013).

27. Verhelst, S., Turner, J. W., Sileghem, L. \& Vancoillie, J. Methanol as a fuel for internal combustion engines. Progress in Energy and Combustion Science 70, 43-88 (2019).

28. Holler Branco, J. E., Holler Branco, D., Aguiar, d. E. M., Caixeta Filho, J. V. \& Rodrigues, L. Study of optimal locations for new sugarcane mills in brazil: Application of a minlp network equilibrium model. Biomass and Bioenergy 127, 105249 (2019).

29. EPE. Brazilian energy balance year 2019. Tech. Rep., Empresa de Pesquisa Energética (2020). URL https://www.epe.gov.br/sites-pt/publicacoes-dados-abertos/publicacoes/ PublicacoesArquivos/publicacao-479/topico-528/BEN2020_sp.pdf. [Online; accessed 2020$12-15]$.

30. IEA. Energy efficiency indicators highlights. Tech. Rep., International Energy Agency (2020). URL https://webstore.iea.org/download/direct/4266?fileName=Energy_Efficiency_Indicators_ Highlights_2020_PDF.pdf. [Online; accessed 2020-12-13].

31. CONAB. Harvest historical series (Série Histórica das Safras ) - sugarcane industry and total area 2005-2020. Tech. Rep., Companhia Nacional de Abastecimento (2020). URL https: //www.conab.gov.br/info-agro/safras/serie-historica-das-safras.

32. González-Garay, A. et al. Plant-to-planet analysis of $\mathrm{co}_{2}$-based methanol processes. Energy \& Environmental Science 12, 3425-3436 (2019). 
33. ANEEL. Siga - sistema de informacões de generacão da aneel. Tech. Rep., Agência Nacional de Energia Elétrica (2020). URL https://app.powerbi.com/view?r= eyJrIjoiNjc4OGYyYjQtYWM2ZC00Yj1lLWJ1YmEtYzdkNTQ1MTc1NjM2IiwidCI6IjQwZ DZmOWI4LWVjYTctNDZhMi05MmQ0LWVhNGU5YzAxNzBIMSIsImMiOjR9. [Online; accessed 2020-10-22].

34. Dunnett, S., Sorichetta, A., Taylor, G. \& Eigenbrod, F. Harmonised global datasets of wind and solar farm locations and power. Scientific Data 7, 130 (2020).

35. Albuquerque, I. et al. Análise das emissões brasileiras de gases de efeito estufa e suas implicações para as metas de clima do brasil 1970-2019. Tech. Rep., Observatório do Clima (2020).

36. Lambin, E. F. \& Meyfroidt, P. Global land use change, economic globalization, and the looming land scarcity. Proceedings of the National Academy of Sciences 108, 3465-3472 (2011).

37. Berkenwald, M. \& Le Feuvre, P. Biofuels in the time of covid-19: Staying the course on clean transport fuels in latin america. Tech. Rep., International Energy Agency (2020). URL https://www.iea.org/commentaries/ biofuels-in-the-time-of-covid-19-staying-the-course-on-clean-transport-fuels-in-latin-america.

38. Gibon, T., Arvesen, A. \& Hertwich, E. G. Life cycle assessment demonstrates environmental co-benefits and trade-offs of low-carbon electricity supply options. Renewable and Sustainable Energy Reviews 76, 1283-1290 (2017).

39. Barros, M. A. S., Magalhães, d. R. G. \& Rui, A. M. Species composition and mortality of bats at the osório wind farm, southern brazil. Studies on Neotropical Fauna and Environment 50, 31-39 (2015).

40. Falavigna, T. J., Pereira, D., Rippel, M. L. \& Petry, M. V. Changes in bird species composition after a wind farm installation: A case study in south america. Environmental Impact Assessment Review 83, 106387 (2020). 
41. Turkovska, O. et al. Land-use impacts of brazilian wind power expansion. Environmental Research Letters (2020).

42. EPE. Cenários de oferta de etanol e demanda de ciclo otto 2020-2030. Tech. Rep., Empresa de Pesquisa Energética (2019).

43. Hannula, I. Co-production of synthetic fuels and district heat from biomass residues, carbon dioxide and electricity: Performance and cost analysis. Biomass and Bioenergy 74, 26-46 (2015).

44. Gnansounou, E., Vaskan, P. \& Pachón, E. R. Comparative techno-economic assessment and lca of selected integrated sugarcane-based biorefineries. Bioresource Technology 196, 364$375(2015)$.

45. CONAB. Perfil do setor do açúcar e do etanol no brasil edição para a safra 2015/16. Tech. Rep., Companhia Nacional de Abastecimento (2019). URL https://www.conab.gov.br/component/ k2/item/download/26992_71d0aa6fb4ab68dfcdd8ef4e5b180138.

46. Andrews, R. W., Stein, J. S., Hansen, C. \& Riley, D. Introduction to the open source pv lib for python photovoltaic system modelling package. In 2014 IEEE 40th Photovoltaic Specialist Conference, 0170-0174 (IEEE, 2014).

47. ECMWF. Era5-land: data documentation (2020). URL https://confluence. ecmwf.int/display/CKB/ERA5-Land\%3A+data+documentation\#ERA5Land: datadocumentation-HowtociteERA5-Land. [Online; accessed 2020-02-20].

48. Ramirez Camargo, L. \& Schmidt, J. Simulation of multi-annual time series of solar photovoltaic power: Is the era5-land reanalysis the next big step? Sustainable Energy Technologies and Assessments 42, 100829 (2020).

49. solargis. Bankable solar data for better decisions (2020). URL https://solargis.com/. [Online; accessed 2020-02-19]. 
50. Gruber, K., Regner, P., Wehrle, S., Zeyringer, M. \& Schmidt, J. Towards a global dynamic wind atlas: A multi-country validation of wind power simulation from MERRA-2 and ERA-5 reanalyses bias-corrected with the Global Wind Atlas. arXiv:2012.05648 [stat] (2020). ArXiv: 2012.05648.

51. Armijo, J. \& Philibert, C. Flexible production of green hydrogen and ammonia from variable solar and wind energy: Case study of chile and argentina. International Journal of Hydrogen Energy 45, 1541-1558 (2020).

52. ANEEL. Sistema georeferenciado do setor elétrico do agência nacional de energia elétrica (2019). URL https://sigel.aneel.gov.br/portal/home/. [Online; accessed 2020-09-07].

53. Denholm, P., Hand, M., Jackson, M. \& Ong, S. Land use requirements of modern wind power plants in the united states. Tech. Rep., National Renewable Energy Lab. (NREL) (2009). URL http://www.osti.gov/servlets/purl/964608-LaTU8c/.

54. Vartiainen, E., Masson, G., Breyer, C., Moser, D. \& Medina, E. R. Impact of weighted average cost of capital, capital expenditure, and other parameters on future utility-scale pv levelised cost of electricity. Progress in Photovoltaics: Research and Applications 28, 439-453 (2020).

55. Danish-Energy-Agency \& Energinet. Technology data -energy plants for electricity and district heating generation. Tech. Rep., Danish Energy Agency (2016). URL https://ens.dk/sites/ ens.dk/files/Analyser/technology_data_catalogue_for_el_and_dh.pdf. [Online; accessed 202012-17].

56. Kruck, O., Crotogino, F., Prelicz, R. \& Rudolph, T. Overview on all known underground storage technologies for hydrogen. Tech. Rep., HyUnder Project (2013).

57. Ikäheimo, J., Kiviluoma, J., Weiss, R. \& Holttinen, H. Power-to-ammonia in future north european 100 renewable power and heat system. International Journal of Hydrogen Energy 43, 17295-17308 (2018). 
58. ZEP. The costs of $\mathrm{co}_{2}$ storage. Tech. Rep., European Technology Platform for Zero Emission Fossil Fuel Power Plants (2011). URL https://zeroemissionsplatform.eu/wp-content/uploads/ CO2-Storage-Report.pdf. [Online; accessed 2020-11-15].

59. Rubin, E. S., Davison, J. E. \& Herzog, H. J. The cost of $\mathrm{co}_{2}$ capture and storage. International Journal of Greenhouse Gas Control 40, 378-400 (2015).

60. Medina Ketzer, J. M., Machado, C. X., Camboim Rockett, G. \& Iglesias, R. S. Brazilian atlas of $\mathrm{CO} 2$ capture and geological storage. Tech. Rep., Center of Excellence in Research and Innovation in Petroleum, Mineral Resources and Carbon Storage (2014). URL https://www.globalccsinstitute.com/archive/hub/publications/190903/ brazilian-atlas-co2-capture-geological-storage.pdf. [Online; accessed 2021-02-17].

61. Eggleston, G., Legendre, B. \& Richard, C. Effect of harvest method and storage time on sugarcane deterioration I: Cane quality changes. International Sugar Journal 103, 331-338 (2001).

62. Shi, X., Liao, X. \& Li, Y. Quantification of fresh water consumption and scarcity footprints of hydrogen from water electrolysis: A methodology framework. Renewable Energy 154, 786-796 (2020).

Supplementary information See Supplementary Information document

Data availability All input and output data for the optimization model will be made available after acceptance under zenodo.

Supplementary information All GAMS, Python and R code necessary to calculate the VRES potential, run the optimization model and create the figures of the paper is available under https://github.com/ inwe-boku/sugar_cane_ethanol_brazil/tree/simulation_vsc.

Author Contributions L.R.C.: Conceptualization, Methodology, Software, Validation, Formal analysis, Investigation, Data Curation, Writing - Original Draft, Writing - Review \& Editing, Visualization, Supervision. G.C.: Conceptualization, Methodology, Validation, Investigation, Writing - Original Draft, Writing 
- Review \& Editing. K.G.: Conceptualization, Methodology, Software, Validation, Investigation, Data Curation, Writing - Original Draft, Writing - Review \& Editing. J.J.: Writing - Original Draft, Writing Review \& Editing. M.K.: Conceptualization, Methodology, Validation, Investigation, Writing - Original Draft, Writing - Review \& Editing, Visualization. O.T.: Conceptualization, Methodology, Validation, Investigation, Writing - Original Draft, Writing - Review \& Editing. E.W.: Conceptualization, Methodology, Validation, Investigation, Writing - Original Draft, Writing - Review \& Editing. J.S.: Conceptualization, Methodology, Software, Validation, Formal analysis, Resources, Data Curation, Writing - Original Draft, Writing - Review \& Editing, Visualization, Supervision, Project administration, Funding acquisition

Acknowledgements We gratefully acknowledge support from the European Research Council ("reFUEL" ERC-2017-STG 758149). G.C. was financed in part by the Coordenação de Aperfeiçoamento de Pessoal de Nível Superior - Brasil (CAPES) - Finance Code 001, and E.W. by the Swedish national strategic research environment Bio4Energy. The simulations were run on the Vienna Scientific Computing Grid (www.vsc.ac. at). We are very thankful for the support provided by the VSC team. We are grateful to Sebastian Wehrle and Marie Claire Brisbois who proofread the manuscript.

Competing Interests The authors declare no competing financial interests.

Correspondence Correspondence and requests for materials should be addressed to L.R.C. (email: luis. ramirez-camargo@boku.ac.at). 
Figures

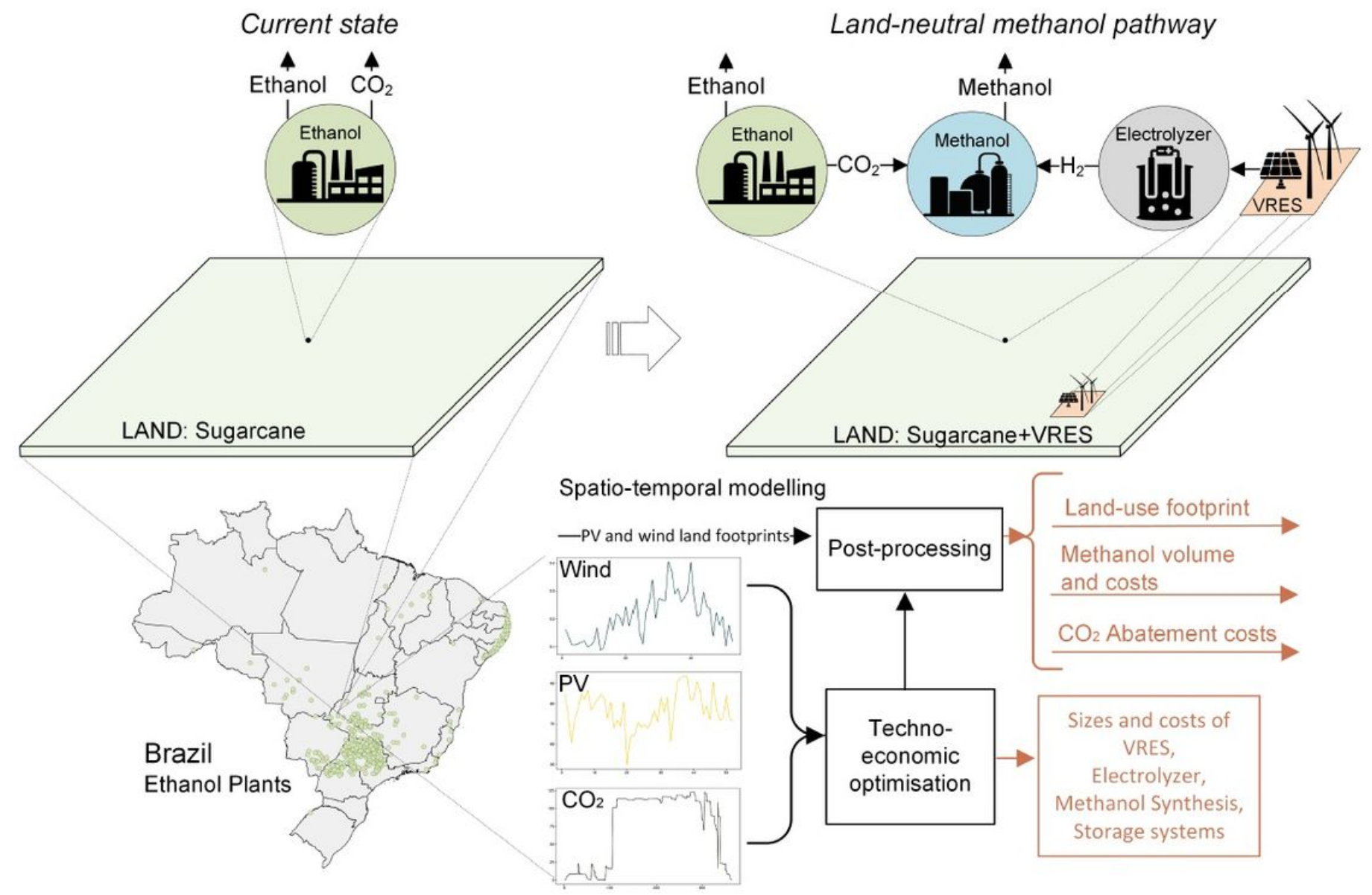

\section{Figure 1}

The proposed land-neutral methanol pathway. 

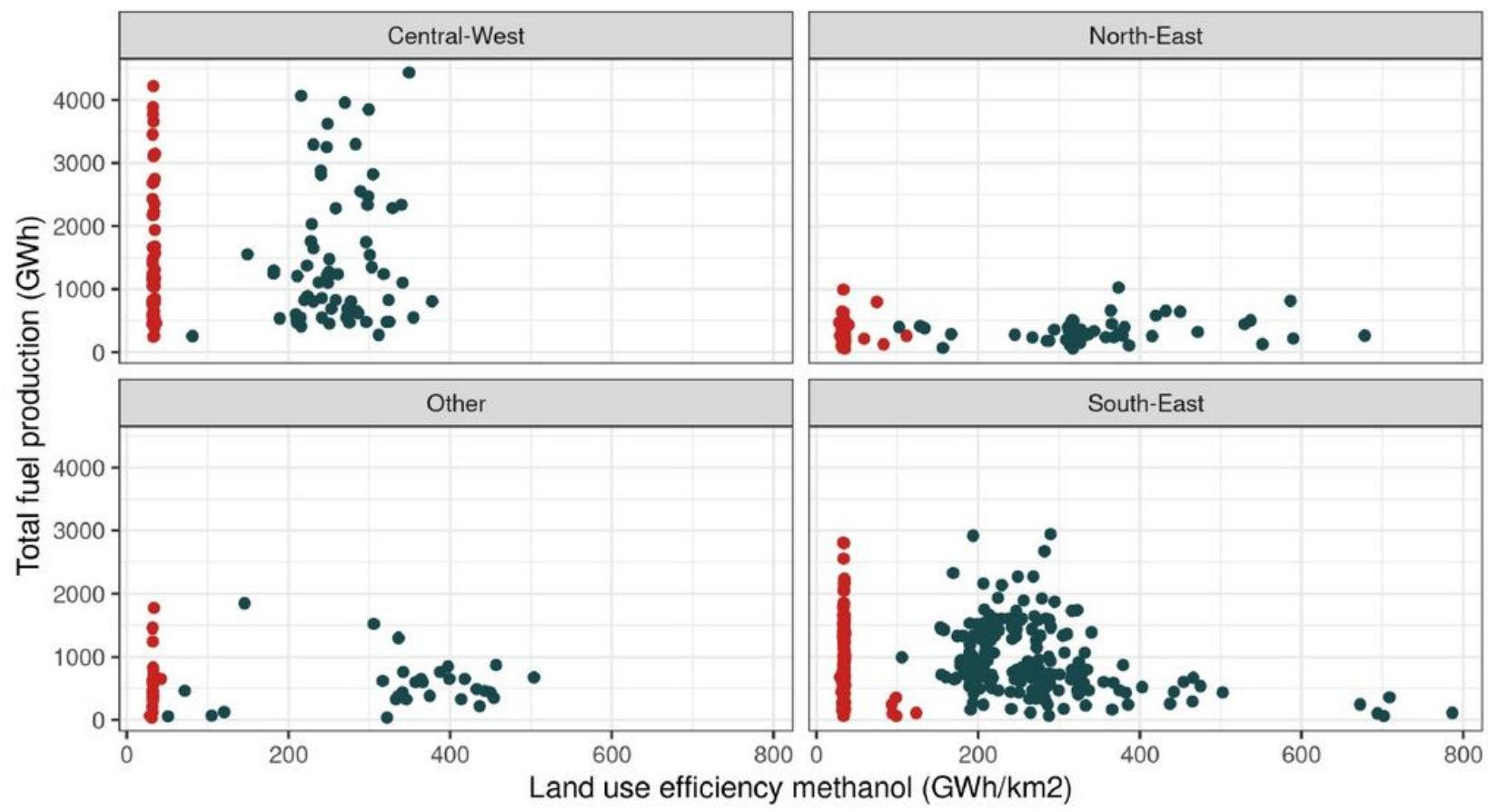

Scenario

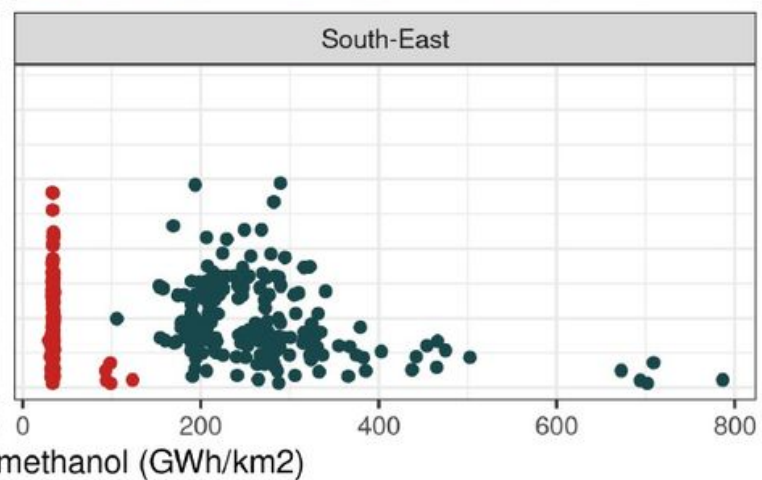

- Solar-Wind

- Wind

\section{Figure 2}

Land-use efficiency of methanol production vs. total fuel production for all Brazilian facilities.
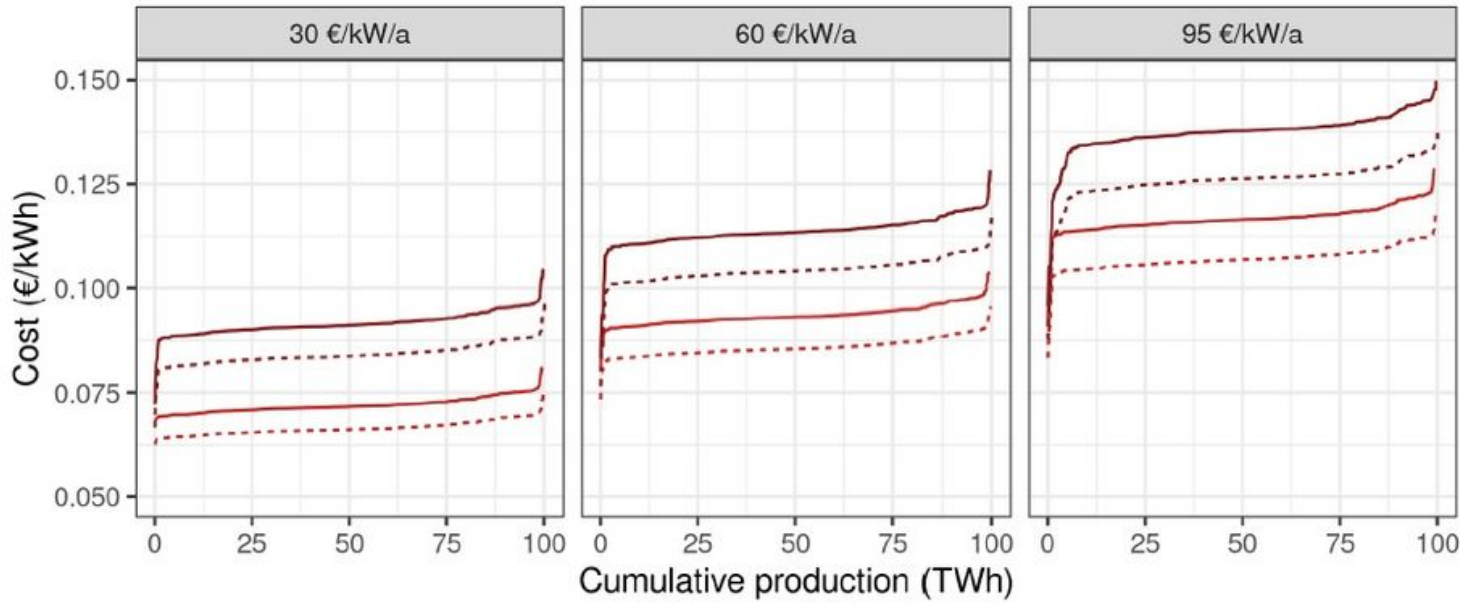

PV costs

- $35 \epsilon / \mathrm{kW} / \mathrm{a}$

- $53 \epsilon / \mathrm{kW} / \mathrm{a}$

Efficiency electrolyzer

$-0.63$

… 0.69
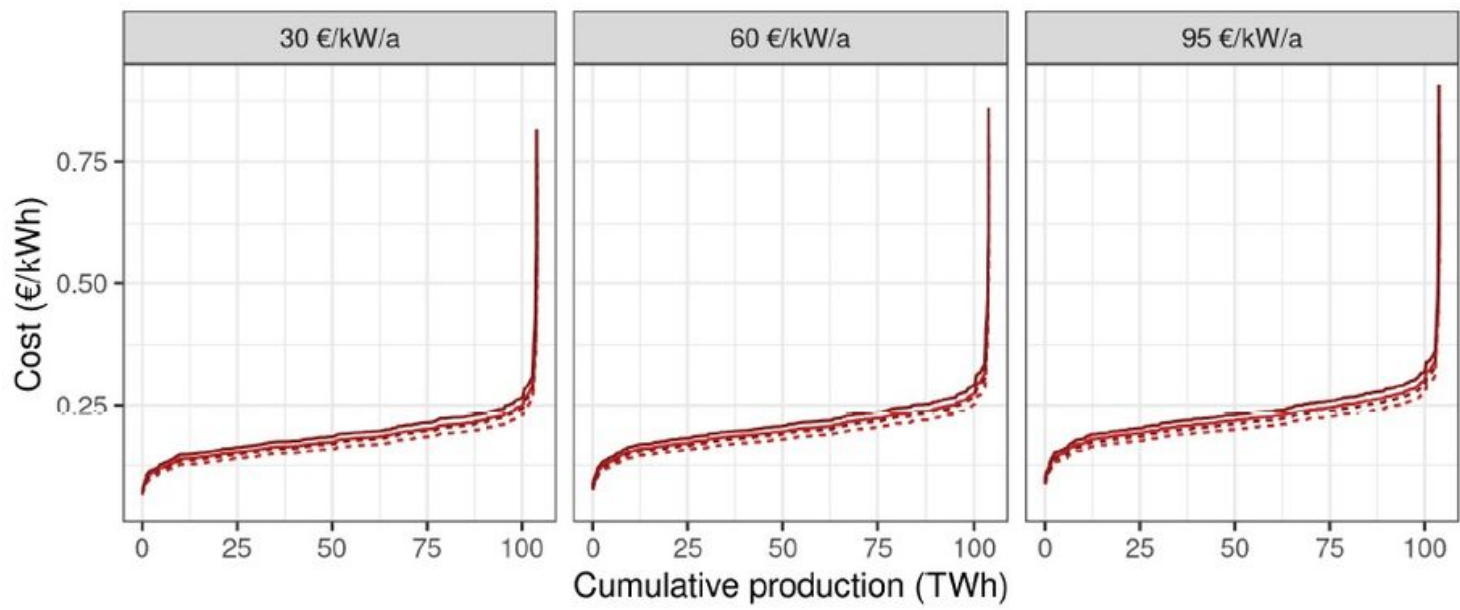

Wind costs

- $118 € / \mathrm{kW} / \mathrm{a}$

- $128 € / \mathrm{kW} / \mathrm{a}$

Efficiency electrolyzer

- 0.63

$\begin{array}{lll}\cdots & 0.69\end{array}$ 


\section{Figure 3}

Cost-supply curves for all scenarios and costs assumptions. Upper: solar-wind scenario. Lower: wind scenario. From left to right: annualized electrolyzer cost assumptions.

\section{Supplementary Files}

This is a list of supplementary files associated with this preprint. Click to download.

- SupplementaryinformationAlandneutralexpansionofBrazilianrenewablefuelproduction15.pdf

- SupplementaryinformationAlandneutralexpansionofBrazilianrenewablefuelproduction15.pdf 